\title{
Prevalence of herpes simplex, Epstein Barr and human papilloma viruses in oral lichen planus
}

\author{
Benay Yildirim ${ }^{1}$, Burcu Sengüven ${ }^{2}$, Cem Demir $^{3}$ \\ ${ }^{1}$ DDs, PhD, Associate Professor, Gazi University, Faculty of Dentistry, Department of Oral Pathology \\ ${ }^{2}$ DDs, PhD, Research Assistant, Gazi University, Faculty of Dentistry, Department of Oral Pathology \\ ${ }^{3}$ DDs, Arpaçay, Kars Dental Hospital
}

Correspondence:

Gazi University, Faculty of Dentistry,

Oral Pathology Department 8.

cadde. 82. sokak EMEK-ANKARA

TURKEY 06510

senguvenb@yahoo.com

Yildirim B, Senguven B, Demir C. Prevalence of herpes simplex, Epstein Barr and human papilloma viruses in oral lichen planus. Med Oral Patol Oral Cir Bucal. 2011 Mar 1;16 (2):e170-4.

http://www.medicinaoral.com/medoralfree01/v16i2/medoralv16i2p170.pdf

Received: 13/03/2010

Accepted: 26/08/2010

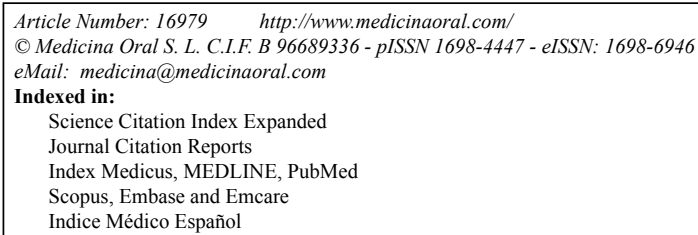

\begin{abstract}
Objectives: The aim of the present study was to assess the prevalence of Herpes Simplex virus, Epstein Barr virus and Human Papilloma virus -16 in oral lichen planus cases and to evaluate whether any clinical variant, histopathological or demographic feature correlates with these viruses.

Study Design: The study was conducted on 65 cases. Viruses were detected immunohistochemically. We evaluated the histopathological and demographic features and statistically analysed correlation of these features with Herpes Simplex virus, Epstein Barr virus and Human Papilloma virus-16 positivity.

Results: Herpes Simplex virus was positive in six (9\%) cases and this was not statistically significant. The number of Epstein Barr virus positive cases was $23(35 \%)$ and it was statistically significant. Human Papilloma virus positivity in 14 cases (21\%) was statistically significant. Except basal cell degeneration in Herpes Simplex virus positive cases, we did not observe any significant correlation between virus positivity and demographic or histopathological features. However an increased risk of Epstein Barr virus and Human Papilloma virus infection was noted in oral lichen planus cases. Conclusions: Taking into account the oncogenic potential of both viruses, oral lichen planus cases should be detected for the presence of these viruses.
\end{abstract}

Key words: Herpes Simplex virus, Epstein Barr virus, Human Papilloma virus, oral lichen planus.

\section{Introduction}

Lichen planus (LP) is a chronic mucocutaneous disease that affects the skin and the oral mucosa with unknown aetiology. Oral lichen planus (OLP) may present reticular, bullous or erosive form and OLP occurs more frequently than the cutaneous form and tends to be more persistent and more resistant to treatment (1). Children are rarely affected. OLP occurs most often in middleaged adults and it is more common among women (2). OLP may arise anywhere in the oral cavity. The buccal mucosa, tongue and gingiva are commonly affected sites, whereas palatal localization is uncommon. The lesions are usually symmetrical, bilateral or may be multiple. It has a variety of clinical presentations, including reticular, papular, plaque-like, atrophic, and ulcerative forms (2). 
Although the etiopathogenesis of lichen planus is unknown, it is generally considered to be an immunologically mediated process that histologically resembles a hypersensitivity reaction. It is characterized by an intense band like T-cell infiltrate in epithelium-connective tissue interface. The factors that initiate LP are unknown, but the mechanism appears to involve several steps as: an initiating factor or event (exogenous/ endogenous antigenic stimulation), focal release of regulatory cytokines, up-regulations of vascular adhesion molecules, recruitment and retention of T-lymphocytes and basal keratinocyte cytotoxicity mediated by T- lymphocytes (3).

Lichen planus is probably of multifactorial origin, possibly induced by drugs or dental materials, psychological factors, infective agents, often idiopathic. The etiopathogenesis appears to be complex, with interactions between genetic, environmental, and lifestyle factors, and interesting new associations, such as with liver disease, have emerged (4).

Viral infections have recently been linked with OLP. Herpes Simplex virus-1 (HSV-1), Cytomegalovirus (CMV), Human Herpes virus-6 (HHV-6) (5, 6), Epstein-Barr virus (EBV) $(5,7,8)$, Human Papilloma virus (HPV) (7) and Hepatitis C virus (HCV) $(5,6)$ are virus types that have been studied in the etiopathogenesis of OLP.

The aim of the present study was to assess the prevalence of HSV, EBV and HPV in histologically diagnosed OLP cases and to evaluate whether any specific clinical variants or histopathological features show a higher frequency of these viruses.

\section{Materials and Methods}

\section{Tissue specimens}

The study was conducted on formalin fixed paraffin embedded tissue specimens of 65 OLP cases. The cases were classified according to age, gender, localization and the histopathological type. Fifteen normal oral mucosal tissue specimens were used as control group.

\section{Immunohistochemical staining}

Five-micrometer thick sections of formalin fixed and paraffin embedded biopsy samples were processed by the avidin-biotin-peroxidase complex (ABC) method. Deparaffinization and rehydratation of the sections were followed by the blocking of endogenous peroxidise activity with incubating the sections in $3 \% \mathrm{H}_{2} \mathrm{O}_{2}$ for 10 minutes. After rinsing with phosphate buffered saline (PBS, pH:7.0), the sections were treated in microwave by antigen retrieval solution (citrate buffer, $\mathrm{pH}: 6.0$ ) for 15 minutes and then the slides were left to cool at room temperature for 30 minutes. Non specific binding was reduced with protein blocking serum (ultra V block, Lab Vision) for 20 minutes. Sections were incubated with Herpes Simplex virus type 2 primary antibody
(HSV II-Ab-1 rabbit polyclonal antibody, Lab Vision), Epstein Barr virus primary antibody (EBV/LMP-Ab-1 mouse monoclonal antibody, Lab Vision), and Human Papilloma virus type 16 primary antibody (HPV-16 Ab-2, mouse monoclonal antibody, Lab Vision) at room temperature for 120 minutes. After rinsing with PBS, the slides were incubated with biotinylated secondary antibody (biotinylated goat anti-polyvalent, Lab Vision) for 30 minutes. The sections were washed with PBS and then the slides were incubated with label (streptavidin peroxidise, Lab Vision) for 30 minutes. The amino ethyl carbazole (AEC, Lab Vision) was used as a chromogen for visualization of the antibody binding. Finally, the sections were counter stained with Mayer's haematoxylin, cleared and mounted.

HSV infected oral mucosal tissue; EBV positive lymphoma tissue and oral mucosal tissue infected with HPV-16,18 were used as positive control tissues for HSV, EBV and HPV-16,18 immunohistochemical staining. The red-brown nuclear staining was accepted as positive staining for each antibody.

We evaluated the histopathological (type of keratinisation, degeneration of basal keratinocytes, inflammation intensity, and thickness of epithelium) and clinical features (age, gender, localization, clinical type) of OLP and statistically analysed correlation of these features with EBV, HSV, and HPV presence. Statistical analyses were made with Pearson Chi-square, Pearson Correlation, Spearmen Correlation and Fisher's Exact Test.

\section{Results}

A total of 65 cases of OLP were utilized in the study. Clinical and immunohistochemical analysis of EBV, HSV and HPV positive cases was given in table 1. Most of the lesions were described as reticular form by the clinicians and major complains about the lesions were burning.

The number of OLP cases that were positive for EBV was $23(35 \%)$ and it was found statistically significant with Pearson Chi-square test $(\mathrm{P}=0.006)$, compared to control subjects (Fig. 1). The mean age in positive cases was 45.8 and there were no statistically significant age or gender differences between the EBV positive and EBV negative cases. Of the $23 \mathrm{EBV}$ positive cases 16 were reticular type, 4 were in plaque and 3 were in erosive form clinically. We did not observe any significant difference between EBV presence and different clinical types of OLP. Also no statistical conclusions could be drawn about localization of OLP and EBV positivity. We also analysed the statistical significance between EBV positivity and histopathological features of OLP such as type of keratinisation, degeneration of basal keratinocytes, inflammation intensity and thickness of epithelium.

HSV was positive in $6(9 \%)$ cases (Fig. 2) and it was not 
Table 1. Demograpfic, and clinical features of virus positive cases.

\begin{tabular}{|c|c|c|c|c|c|c|}
\hline NO & LOCALIZATION & AGE & GENDER & HPV & HSV & EBV \\
\hline 1. & Buccal mucosa & 26 & $\mathrm{~F}$ & - & - & + \\
\hline 2. & Buccal mucosa & 41 & M & + & - & - \\
\hline 3. & Buccal mucosa & 51 & $\mathrm{~F}$ & - & - & + \\
\hline 4. & Lip & 73 & M & - & - & + \\
\hline 5. & Buccal mucosa & 58 & $\mathrm{~F}$ & + & - & - \\
\hline 6. & Buccal mucosa & 25 & $\mathrm{~F}$ & - & - & + \\
\hline 7. & Unknown & Unknown & $\mathrm{F}$ & - & - & + \\
\hline 8. & Buccal mucosa & 39 & M & - & - & + \\
\hline 9. & Buccal mucosa & 41 & $\mathrm{~F}$ & - & - & + \\
\hline 10. & Buccal mucosa & Unknown & $\mathrm{F}$ & - & - & + \\
\hline 11. & Unknown & 39 & $\mathrm{~F}$ & + & - & - \\
\hline 12. & Buccal mucosa & 19 & $\mathrm{~F}$ & + & - & - \\
\hline 13. & Lip & 36 & $M$ & + & - & - \\
\hline 14. & Gingiva & Unknown & $\mathrm{F}$ & + & + & + \\
\hline 15. & Buccal mucosa & 56 & M & - & - & + \\
\hline 16. & Buccal mucosa & 38 & $\mathrm{~F}$ & + & - & - \\
\hline 17. & Buccal mucosa & 48 & $\mathrm{~F}$ & - & - & + \\
\hline 18. & Buccal mucosa & 62 & $M$ & - & + & + \\
\hline 19. & Buccal mucosa & Unknown & $\mathrm{F}$ & - & - & + \\
\hline 20. & Buccal mucosa & 48 & $\mathrm{~F}$ & - & - & + \\
\hline 21. & Buccal mucosa & 52 & $\mathrm{~F}$ & + & + & - \\
\hline 22. & Buccal mucosa & Unknown & $\mathrm{M}$ & + & - & + \\
\hline 23. & Buccal mucosa & 44 & M & - & + & + \\
\hline 24. & Gingiva & 25 & $\mathrm{~F}$ & + & - & - \\
\hline 25. & Gingiva & 61 & $M$ & - & + & - \\
\hline 26. & Buccal mucosa & Unknown & $\mathrm{F}$ & + & - & + \\
\hline 27. & Unknown & 58 & M & + & - & + \\
\hline 28. & Buccal mucosa & 51 & $M$ & - & + & + \\
\hline 29. & Buccal mucosa & 49 & $\mathrm{~F}$ & + & - & + \\
\hline 30. & Buccal mucosa & 46 & $M$ & + & - & + \\
\hline 31. & Buccal mucosa & 38 & $\mathrm{M}$ & - & - & + \\
\hline 32. & Retromolar & 24 & $M$ & - & - & + \\
\hline
\end{tabular}

statistically significant $(\mathrm{P}=0.588)$. The mean age was 48 for HSV positive patients. There was not any correlation between HSV positivity and localization, clinical type or age of patients. We determined a significant correlation between degeneration score 2 and HSV positivity $(\mathrm{P}=0.023)$.

HPV 16 was immunohistochemically positive in 14 cases $(21 \%)$ (Fig. 3). It was statistically significant $(\mathrm{P}=0.048)$, compared to control subjects. There was a female predilection (9:5) but not statistically significant and the mean age was 47.8 in HPV positive OLP group. Clinically 2 cases were erosive, 5 were plaque and 7 were reticular type of OLP. No statistical conclusions could be drawn about localization, age, gender, clinical form and HPV positivity. We could neither determine any significant correlation between HPV positivity and histopathological features of OLP.

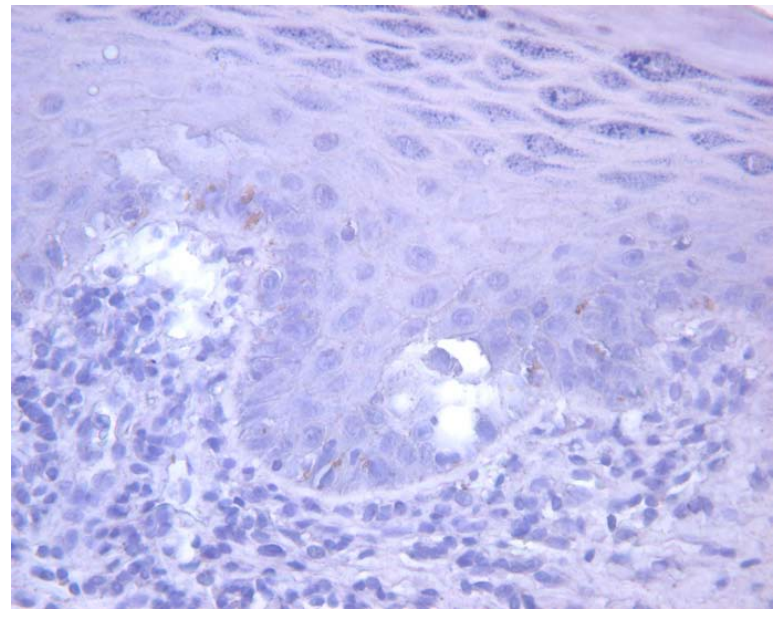

Fig. 1. EBV positivity in keratinocytes. 


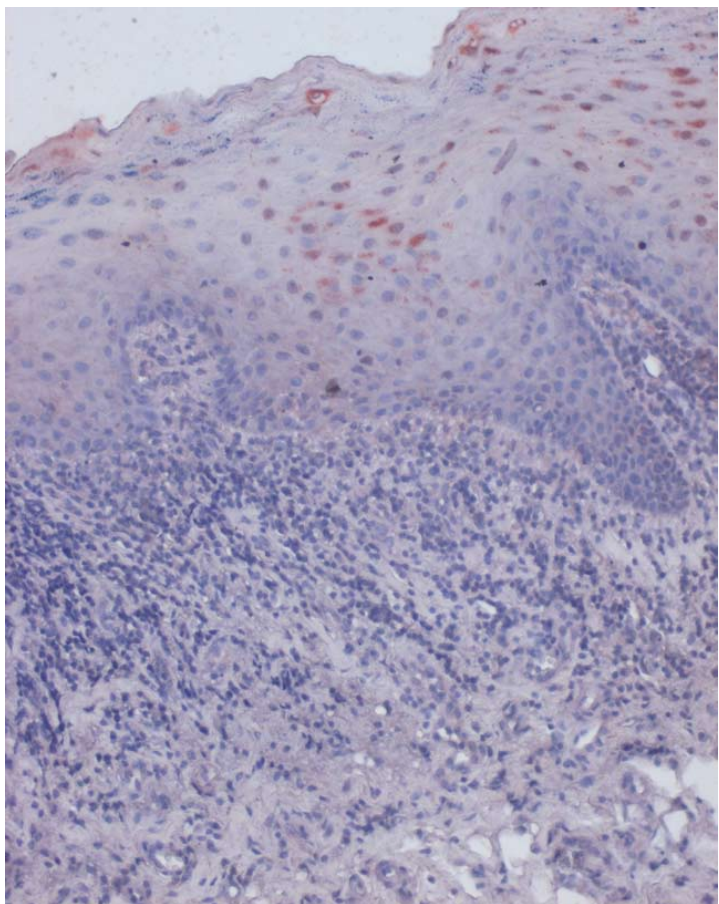

Fig. 2. HSV positivity in spinous layer.

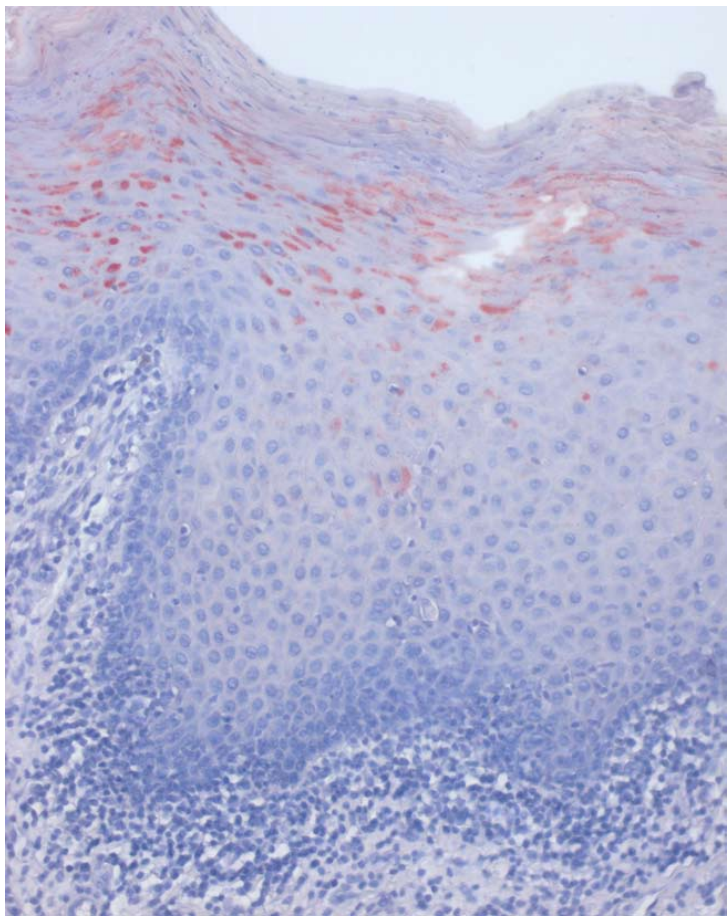

Fig. 3. Strong red staining in HPV positive cells.
Four cases were positive for both EBV and HSV, 1 case was positive for both HPV and HSV, 3 cases were positive for both HPV and EBV.

The control group was totally negative for all 3 viruses.

\section{Discussion}

HSV-1 infections are common vesicular lesions of the skin and mucosa. HSV-1 has occasionally been found in OLP, mainly in erosive lesions in small series (4). Cox et al. reported $50 \% \mathrm{HSV}-1$ positivity in OLP, in 4 cases (5). De Vries et al. could not detect any HSV-1 DNA in LP in 18 cases (8). Like Oflatharta et al.(7), they all have concluded that HSV has no causative role in the etiopathogenesis of OLP. In the present study 6 of 65 OLP cases $(9 \%)$ were positive for HSV-1 and this was not statistically significant.

The antibody used in the present study for HSV reacts with antigens common for HSV type 1 and type 2 . HSV-2 has a predilection for genital mucosa however it may also cause oral lesions secondary to oral-genital contact. The antibody reacts with all the major glycoprotein present in the viral envelope and at least one core protein.

In the present study we couldn't find any correlation between HSV positivity and clinical features of OLP. On the contrary to our prospect, except 1 case, HSV positive lesions were clinically in reticular or plaque form. The only positive correlation between the histological features and HSV positivity was in basal cell degeneration (score 2). As HSV gives rise to ulcerative lesions, prominent basal cell degeneration might be due to its ulcerative capacity.

This low percentage of HSV presence in lesional OLP does not imply a causative relation between the two. Possibly this data suggested that HSV presence in OLP might be secondary to a locally altered immune response.

EBV is a member of Human Herpes virus family that is widespread in the normal population, with over $90 \%$ of adults being seropositive. It is able to be persistent lifelong in the human body.

Currently studies on EBV in OLP cases are very limited. Sand et al.(9) reported $26.1 \%$ significant EBV positivity compared to control subjects $(\mathrm{p}=0.024)$ and pointed out EBV infection in OLPs. Also Cruz (10) who observed specific EBV DNA in some OLP specimens suggested that EBV may be involved in the pathogenesis of OLP. In the present study the number of OLP cases that were positive for EBV was $23(35 \%)$ and this was statistically significant $(\mathrm{P}=0,006)$. This high EBV positivity in the lesional OLP suggested that EBV may play a role in the ethiopathogenesis of OLP. However whether the EBV infection is involved in the etiopathogenesis of OLP or it is secondary to local immunosuppression is difficult 
to say. Future molecular studies have yet to be carried out.

Despite several studies reporting high frequencies of HPV positivity in OLP cases $(5,11)$ the role of HPV in OLP etiopathogenesis is still controversial and further studies are required. In the present study HPV-16 positivity in 14 cases $(21 \%)$ was statistically significant $(\mathrm{P}=0.048)$, compared to control subjects in the series of 65 cases. In the literature higher frequencies $(27.3 \%$, $42.0 \%, 65.0 \%)(12-14)$ have been reported but many of them were for pan HPV. Also these variations may be due to sensitivity and specificity of different methods used. Our results were consistent with that of Campisi et al. (19\%) (15). We also evaluated a possible association of HPV positivity with different variants of OLP. Actually Jontel and González-Moles et al. $(14,16)$ reported relatively high HPV frequencies in atrophicerosive forms of OLP. In our study no significant difference was observed in different variants of OLP. Demographic data was also consistent with that of Sand et al. (12). The demographic data of the HPV positive patients were not statistically different from the negative patients. We could neither determine any significant correlation between HPV positivity and histopathological features of OLP. Although high HPV 16 positivity (21\%) in the lesional OLP was found statistically significant, its causative role is controversial. Yet we cannot ignore an increased risk of HPV 16 infection in patients with OLP.

Taking in the account the oncogenic potential of both EBV and HPV 16, OLP cases should be detected for the presence of these viruses, along with an adequate long term follow up of the lesions that are found positive. The examination of OLP specimens for oncogenic viruses is certainly meritorious but currently is expensive and not yet readily available in many centres. We also believe it will be the way of the future but at this point is beyond the scope of the oral medicine and oral pathology specialists or dermatologists more so than general dentists.

\section{References}

References with links to Crossref - DOI

1. Edwards PC, Kelsch R. Oral lichen planus: clinical presentation and management. J Can Dent Assoc. 2002;68:494-9.

2. Zakrzewska JM. Re: Mollaoglu N. Oral lichen planus: a review. Br J Oral Maxillofac Surg 2000;38:370-377.

3. Dissemond J. Oral lichen planus: an overview. J Dermatolog Treat. 2004;15:136-40.

4. Lodi G, Scully C, Carrozzo M, Griffiths M, Sugerman PB, Thongprasom K. Current controversies in oral lichen planus: report of an international consensus meeting. Part 1. Viral infections and etiopathogenesis. Oral Surg Oral Med Oral Pathol Oral Radiol Endod. 2005;100:40-51.

5. Cox M, Maitland N, Scully C. Human herpes simplex-1 and papillomavirus type 16 homologous DNA sequences in normal, potentially malignant and malignant oral mucosa. Eur J Cancer B Oral Oncol. 1993;29B:215-9.

6. Míco-Llorens JM, Delgado-Molina E, Baliellas-Comellas C, Berini-Aytés L, Gay-Escoda C. Association between B and/or C chronic viral hepatitis and oral lichen planus. Med Oral. 2004;9:183-90. 7. OFlatharta C, Flint SR, Toner M, Butler D, Mabruk MJ. Investigation into a possible association between oral lichen planus, the human herpesviruses, and the human papillomaviruses. Mol Diagn. 2003;7:73-83.

8. De Vries HJ, van Marle J, Teunissen MB, Picavet D, Zorgdrager $\mathrm{F}$, Bos JD, et al. Lichen planus is associated with human herpesvirus type 7 replication and infiltration of plasmacytoid dendritic cells. $\mathrm{Br}$ J Dermatol. 2006;154:361-4.

9. Sand LP, Jalouli J, Larsson PA, Hirsch JM. Prevalence of EpsteinBarr virus in oral squamous cell carcinoma, oral lichen planus, and normal oral mucosa. Oral Surg Oral Med Oral Pathol Oral Radiol Endod. 2002;93:586-92.

10. Cruz I, Van den Brule AJ, Steenbergen RD, Snijders PJ, Meijer CJ, Walboomers JM, et al. Prevalence of Epstein-Barr virus in oral squamous cell carcinomas, premalignant lesions and normal mucosa--a study using the polymerase chain reaction. Oral Oncol. 1997;33:182-8.

11. Maitland NJ, Cox MF, Lynas C, Prime SS, Meanwell CA, Scully C. Detection of human papillomavirus DNA in biopsies of human oral tissue. Br J Cancer. 1987 ;56:245-50.

12. Sand L, Jalouli J, Larsson PA, Hirsch JM. Human papilloma viruses in oral lesions. Anticancer Res. 2000;20:1183-8.

13. Vesper M, Riethdorf S, Christoph E, Ruthke A, Schmelzle R, Löning T. [Detection of human papillomavirus (HVP)-DNA in oral manifestation of lichen planus]. Mund Kiefer Gesichtschir. 1997;1:146-9.

14. Jontell M, Watts S, Wallström M, Levin L, Sloberg K. Human papilloma virus in erosive oral lichen planus. J Oral Pathol Med. 1990;19:273-7.

15. Campisi G, Giovannelli L, Aricò P, Lama A, Di Liberto C, Ammatuna P, et al. HPV DNA in clinically different variants of oral leukoplakia and lichen planus. Oral Surg Oral Med Oral Pathol Oral Radiol Endod. 2004;98:705-11.

16. González-Moles MA, Rodríguez-Archilla A, Ruiz Avila I, Esteban F, González-Moles S, Bravo M. Presence of HPV 16 sequences in oral lichen planus lesions. Bull Group Int Rech Sci Stomatol Odontol. 1998;40:92-7. 